\title{
PENDIDIKAN KARAKTER DALAM NASKAH GENDING KARESMEN SI KABAYAN JEUNG RAJA JIMBUL KARYA WAHYU WIBISANA (Kajian Struktur dan Psikosastra)
}

\author{
Sanjani Rahimakumulloh \\ SMK Negeri 7 Bandung \\ Pos-el: Sanjanirahimakumulloh@ymail.com
}

\begin{abstract}
Abstrak
Penelitian ini dilatarbelakangi oleh fakta bahwa terdapat aspek psikologis Si Kabayan yang perlu dijelaskan dalam naskah gending karesmen. Kabayan tidak serta merta mempunyai karakter yang khas, kalau tidak ada tokoh lainnya. Tujuan utama dalam penelitian ini untuk mendeskripsikan nilai pendidikan karakter yang ada dalam naskah ini. Dalam penelitian ini, metode yang digunakan adalah metode deskriptif dengan teknik dokumentasi dan analisis unsur langsung untuk mendeskripsikan struktur sastra, yang meliputi struktur naratif, struktur dramatik, dan sastra lagu, serta aspek psikosastra dalam naskah gending karesmen Si Kabayan jeung Raja Jimbul. Hasil penelitian ini meliputi tiga hal, pertama, struktur naratif yang meliputi téma, téma dalam naskah ini adalah kedaulatan rakyat, lalu fakta cerita meliputi tokoh yang berjumlah 7 tokoh, latar yang berjumlah dua latar, serta alur yang dipakai adalah alur maju. Sarana sastra dalam naskah ini meliputi gaya basa yang berjumlah 8 gaya basa, serta sudut pandang yang dipakai adalah sudut pandang orang ketiga. Kedua, struktur dramatik meliputi prolog yang dicantumkan dalam naskah ini, dialognya berjumlah 182 dialog, tidak terdapat babak, hanya adegan yang berjumlah 12 adegan, wawancang dalam naskah ini sebanyak 22 wawancang, lalu terdapat 1 solilokui, serta tidak ditemukan epilog dan aside. Sastra lagu yang terdapat dalam naskah ini sebanyak 3 bentuk. Ketiga, yaitu kajian terhadap aspek psikosastra yang meliputi aspek kebutuhan rasa aman jumlahnya 12, aspek kebutuhan memiliki-dimiliki jumlahnya 2, aspek kebutuhan fisiologis jumlahnya 7, kebutuhan terhadap penghargaan jumlahnya 6, dan kebutuhan aktualisasi diri jumlahnya 5. Setelah melalui pengkajian aspek struktur dan psikosastra, nilai pendidikan karakter yang terdapat dalam naskah ini sebanyak 12 nilai.
\end{abstract}

Kata Kunci: pendidikan karakter, gending karesmen, psikosastra

\section{THE CHARACTER EDUCATION IN THE TEXT OF GENDING KARESMEN SI KABAYAN JEUNG RAJA JIMBUL OF WAHYU WIBISANA (The Study of Structure and Psycholiterature)}

\begin{abstract}
There are several psychological aspects of Si Kabayan that need to be explained in the text of Gending Karesmen. Kabayan does not essentially have a distinctive character without the other figures. The main objective of this study was to describe the educational value of the characters in the text. This study employed a descriptive method with documentation technique and direct elemental analysis for describing the literary structure. The literary structure includes a narrative structure, dramatic structure, and songs literature. In addition, this study was also aimed to reveal psycholiterature aspects of the manuscript of gending karesmen Si Kabayan Jeung King Jimbul. The results of the study include three things. The first is a narrative structure that includes the theme of the people sovereignty, the fact that the story includes 7 figures, two story backgrounds, and the forward plot. Literary devices in the
\end{abstract}


script include eight language styles. Meanwhile, the viewpoint used in the story is the thirdperson perspective. The second, the dramatic structure includes a prologue set forth in this text. There are 182 dialogs, without round. It only covers 12 scenes. The text has 12 wawancangs, one soliloquy, without epilogue and aside. Literary songs contained in this text as much as 3 forms. Third, the study of aspects psikosastra covering aspects of security needs in number 12, the aspect needs to have-owned in number 2, number 7 aspects of physiological needs, the need to award the number 6, and self-actualization needs amount 5. After assessment aspects of the structure and psikosastra, character education values contained in this text as much as 12 values. There are three forms of songs literature. The third, the study on the aspects of psycholiterature cover 12 aspects of security need, two aspects of need to have, 7 aspects of physiological need, 6 aspects of award need, and 5 aspects of selfactualization needs. Based on the assessment of structural and psycholiterature aspects, there are 12 character education values contained in this text.

Keywords: character education, gending karesmen, psycholiterature.

\section{PENDAHULUAN}

Dewasa ini, sebagian besar masyarakat beranggapan bahwa drama hanya sebuah pertunjukan yang ditampilkan di panggung atau media, khususnya televisi. Padahal, menurut Hasanudin (1996: 1) drama merupakan salahsatu genre sastra yang memiliki dua dimensi karakter, yaitu selaku genre sastra dan seni lakon. Sebab dibangun oleh dua dimensi karena di dalam drama terdapat unsur sastra dan unsur pertunjukan. Hal ini sesuai dengan pendapat Iskandarwassid (1996: 33) yang menjelaskan bahwa drama yaitu karangan sastra yang menampilkan cerita atau lakon berbentuk dialog untuk kemudian dimainkan oleh para aktor dalam suatu pagelaran. Jadi sangat jelas bahwa drama merupakan genre sastra seperti cerpen dan novel yang bisa dinikmati, meskipun yang menjadi tujuan akhir drama adalah pertunjukkan atau pagelaran.

Di Jawa Barat terdapat bermacammacam jenis drama, dintaranya longsér, topéng banjét, sandiwara, ubrug, uyeg, dan gending karesmén. Khusus untuk gending karesmen, pertunjukkan ini memiliki bentuk yang berbeda dibanding drama yang lainnya, utamanya dalam dialognya yang dinyanyikan.

Dalam segi pagelaran, gending karesmen bisa disebut pagelaran kolosal, karena di dalam pagelaran gending karesmen merupakan gabungan beberapa seni, yaitu seni suara, seni music, seni rupa, seni pertunjukkan, seni peran, seni tari, dan seni sastra. Menurut Sopandi (1994: 141), dalam pagelaran gending karesmen semua aktor berdialog dengan cara bernyanyi (sekaran) yang bersumber dari kawih atau tembang, dan diiringi oleh karawitan tergantung kebutuhan teks dan ceritanya. Lakon atau teks cerita dalam pertunjukkan gending karesmen berbentuk prosa liris.

Naskah gending karesmen merupakan salahsatu bentuk karya sastra yang oleh pengarang direfleksikan dalam bentuk imajinatif, serta memiliki nilai-nilai positif. Oleh sebab itu, para pemain atau aktor perlu mendalami isi naskah sebelum menggelar pertunjukkan. Karena para pemain harus memahami maksud dan tujuan yang ingin disampaikan pengarang, lalu menyampaikan nilai-nilai yang terdapat dalam naskah kepada masyarakat. Tidak hanya dalam pegelaran, hasil kajian naskah gending karesmen bisa dimanfaatkan untuk kepentingan pendidikan, khususnya pendidikan karakter.

Menurut Koesoema (2007: 114), secara psikologis dan sosial kultural, membangun karakter dalam diri individu merupakan fungsi dari semua potensi individu manusia (kognitif, afektif, dan psikomotorik) dalam konteks interaksi sosial (dalam keluarga, pendidikan, dan masyarakat) yang berlangsung selamanya. Implementasi keberlangsungan pendidikan karakter merupakan 
upaya meningkatkan kesesuaian dan mutu pendidikan. Empat hal yang dijadikan rujukan berlangsungnya pendidikan karakter, yaitu:

1) olah hati atau qolbu (spiritual and emotional development), meningkatkan asset yang berhubungan dengan nilai agama (ketuhanan, habluminallah) supaya dapat bekerja dan melakukan segala hal dengan ikhlas.

2) olah rasa atau karsa (affective and creativity development), meningkatkan asset yang berhubungan dengan sesama manusia (hablumminanas), agar mampu hidup berdampingan dengansesama.

3) olah pikir atawa dzikir (intellectual development), meningkatkan asset yang berhubungan dengan akal, agar dapat berpikir baik dan cerdas.

4) olah raga dan kinestetik (physical and kinesthetic development), meningkatkan asset fisik untuk selalu sehat dan mampu bekerja dengan baik.

Proses berlangsungnya pendidikan karakter tidak lepas dari tanggung jawab elemen bangsa, termasuk para pemain dalam gending karesmen. Nilai-nilai yang disampaikan dalam naskah gending karesmen serta pagelarannya bisa jadi sarana pembudayaan dan pemanusiaan.

Tidak berbeda dengan bentuk sastra lainnya, naskah gending karesmen memiliki struktur cerita, baik itu tema atau pelaku. Naskah gending karesmen juga merupakan medium untuk menyampaikan nilai pendidikan karakter yang mempunyai unsur imajinatif dan nilai estetik. Nilai pendidikan karakter tentunya ada dalam diri pelaku, yang perbuatan dan ucapnya menjadi cerminan bagi para pembaca. Sebab, para pelaku dalam karya sastra merupakan refleksi dari kehidupan nyata yang diciptakan dan diolah oleh sastrawan dengan baik.

Salah satu sastrawan yang terjun langsung ke dunia gending karesmen yaitu Wahyu Wibisana, yang produktif membuat naskah gending karesmen. Selain membuat teks cerita, Wahyu Wibisana menyutradarai pertunjukkan gending karesmen yang bekerja sama dengan seniman-seniman Sunda terkenal, diantaranya Mang Koko, R.T.A Sunarya, Enoch Atmadibrata, dan Entjar Tjarmedi. Naskah-naskah gending karesmen karya Wahyu Wibisana yang pernah dipagelarkan yaitu Mundinglaya Saba Langit (1962), Inten Déwata (1963), Galunggung Ngadeg Tumenggung (1964), Si Kabayan (1963), Si Kabayan jeung Raja Jimbul (1964), Isukan Raja Rék Mulang (1965-1966), Aki Nini Balangantrang (1967) (Natapraja, 2003: 219-215). Naskahnaskah gending karesmen karya Wahyu Wibisana termasuk naskah yang inovatif, sebab ceritanya tidak hanya mengadaptasi dari wawacan dan cerita pantun, tapi juga dari dongeng, yang tertuang dalam naskah Si Kabayan dan Si Kabayan jeung Raja Jimbul (Natapraja, 2003:223).

Dalam naskah Si Kabayan jeung Raja Jimbul, banyak nilai-nilai pendidikan karakter yang digambarkan oleh para pelakunya. Oleh sebab itu, semua pelaku perlu dipelajari lebih dalam dalam hal aspek psikologisnya, karena jalan pikiran tokoh yang merupakan refleksi dari manusia nyata yang saling berhubungan dengan perbuatannya. Salah satu contohnya ialah Kabayan, tokoh yang terkenal akan kekonyolannya. Dalam satu cerita, Kabayan digambarkan sebagai tokoh yang malas, miskin, dan terkadang menyebalkan. Tapi dalam cerita yang lainnya, Kabayan digambarkan sebagai tokoh yang cerdas, gesit, dan banyak akal (Sumardjo, 2014: 25).

Gambaran tokoh seperti itu perlu pelajari lebih luas berdasarkan aspek psikisnya, agar tidak menimbulkan pemahaman psikologis yang dangkal, perlu dipelajari apa penyebab satu tokoh melakukan perbuatan seperti itu,dan bagaimana hubungan kelakuan satu tokoh dengan tokoh yang lainnya (Endraswara, 2007: 12). Satu pelaku tidak dinilai hanya dari data teksnya saja, tapi lebih dalam lagi, masuk ke alam metafisikanya, dari situlah dapat dipahami nilai-nilai yang ada dalam satu pelaku (Endraswara, 2007: 86). Kajian psikologi sastra cocok untuk mendeskripsikan karak- 
ter-karakter pelaku serta menyelami alam metafisika tokoh yang ada dalam naskah "Si Kabayan jeung Raja Jimbul" untuk mendapatkan nilai-nilai pendidikan karakter yang terkandung di dalamnya.

Sudah ada beberapa penelitian mengenai Si kabayan, yang terbaru adalah buku karya Jakob Sumardjo yang berjudul Paradoks Cerita-cerita Si Kabayan (2014). Dalam buku ini, dijelaskan kehidupan Si Kabayan dilihat dari sudut pandang paradoks atau sebaliknya.

\section{METODE}

Penelitian ini termasuk penelitian kualitatif dengan memakai metode deskriptif analisis. Metode ini dianggap cara dan strategi untuk memahami realitas, dan langkah-langkah sistematis untuk menganalisis pola sebab-akibat. Metode ini cocok untuk mengidentifikasi dan mendeskripsikan nilai pendidikan karakter yang ada dalam naskah gending karesmen "Si Kabayan jeung Raja Jimbul" karya Wahyu Wibisana, berdasarkan struktur naratif (tema, fakta carita, dan sarana sastra) dan struktur dramatik (prolog, dialog, pembabakan, adegan, wawancang, solilokui, aside, epilog), dan aspek psikosastra para tokohnya berdasarkan teori Maslow yang meliputi kebutuhan fisiologis, kebutuhan terhadap rasa aman, kebutuhan terhadap penghargaan, dan kebutuhan aktualisasi diri.

\section{HASIL DAN PEMBAHASAN}

Ada empat poin dalam pembahasan ini, yang pertama struktur naratif yang meliputi tema, fakta carita (alur, tokoh dan penokohan, latar), sarana sastra (gaya bahasa dan sudut pandang). Kedua struktur dramatik yang meliputi (prolog, dialog, pembabakan, adegan, wawancang, solilokui, aside, epilog) dan sastra lagu. Keempat aspek psikologi sastra, lalu kelima nilai pendidikan karakter.

\section{Struktur Naratif \\ Tema}

Tema yang terdapat dalam naskah gending karesmen "Si Kabayan jeung Raja Jimbul" adalah tema kedaulatan rakyat. Penjelasan akan hal ini terdapat di bawah ini.

Si Kabayan ungkleuk-ungkleukan dina korsi goyang. Pamajikanana keur diuk dina babancik bari kekerod. Totopong hideung ngagantung kénéh dina panyawéran...

\section{KABAYAN \\ Lalagedayan deuh... Lalagedayan E... Ngeunah pipikiran}

AMBU KABAYAN
$\begin{aligned} & \text { Nunang naming nuninang nunang } \\ & \text { nanung }\end{aligned}$

KABAYAN

Hirup ukur laladangan, dadagangan

\author{
AMBU KABAYAN \\ Durang durirang, during durarung...

\section{KABAYAN} \\ Hirup cukup héhéotan, ngahéotan. \\ Héhéotan deuh... ngahéotan \\ E... bagja dararatang. \\ (Adegan I, hal 1)
}

Dari dialog di atas, terlihat bahwa Kabayan dan Ambu Kabayan termasuk kriteria tokoh yang bebas, tokoh yang sudah berdaulat dalam pekerjaan dan masalah ekonomi. Pikiran mereka sudah terbebas dari tetek bengek dan rasa takut akan kesulitan ekonomi. Dalam masalah pekerjaan pun, Kabayan dan Ambu Kabayan sudah terbebas dari paksaan. Entah itu dari pihak tetangga maupun pihak yang berkuasa. Kabayan dan Ambu Kabayan melakukan sutau pekerjaan bukan karena paksaan, tapi karena kesadaran. Mereka memilih pekerjaan tanpa paksaan, dan meman- 
faatkan sumber yang ada, tentunya hidup akan lebih bahagia.

Dua Gulang-Gulang marawa tumbak daratang $\mathrm{ka}$ hareupeun imah $\mathrm{Si}$ Kabayan...

GULANG-GULANG

Raja Jimbul ka dieu bade ngalangkung KABAYAN

Nya pék baé, moal ieuh dicaram

\section{GULANG-GULANG}

Raja Jimbul ka dieu bade ngalanglang

\section{KABAYAN}

Nya hol baé, moal dihalang-halang (adegan IV, hal. 3)

Dalam catatan di atas terlihat sikap Kabayan yang mengakui kebebasan orang lain. Dia tidak menghalangi siapa saja yang ingin melewati dirinya yang sedang berdiam di depan rumah. Kabayan pun menghormati kedaulatan orang lain tanpa harus meninggalkan siapa dirinya. Entah itu raja atau rakyat biasa, tidak membedabedakan.

Gulang-Gulang leuleumpangan deui. Tuluy nyampeurkeun deui $\mathrm{ka} S \mathrm{Si}$ Kabayan.

GULANG-GULANG

Gancang buruan sapuan!

KABAYAN

Biasana ogé tara.

GULANG-GULANG

Enya ayeuna sapuan!

KABAYAN

Biasana ogé embung.

GULANG-GULANG

Enya ayeuna purunkeun.

Hayoh! Gancang!

Ayeuna purunkeun.

\author{
KABAYAN \\ Purun mah aya di uing \\ Niat ogé uing nu boga \\ Eunteu ulun enteu iat \\ Aduh... ngeunah nguliat... \\ (adegan IV, hal. 3)
}

Sikap Si Kabayan dalam adegan di atas memperlihatkan bahwa manusia mempunyai kedaulatan masing-masing, terkadang tidak bisa dipaksa untuk menuruti kehendak orang lain. Jika satu orang merasa tidak perlu melakukan suatu pekerjaan, untuk apa dilakukan, bisa jadi kalau dilakukan malah merugikan orang lain. Dari catatan di atas juga terlihat bahwa manusia mempunyai batas untuk tidak mengganggu kedaulatan orang lain. Hal ini terlihat dalam kalimat purun mah aya di uing, niat ogé uing nu boga (mau-tidaknya tergantung diri sendiri, niat juga saya yang punya).

\section{Alur}

Cerita Si Kabayan menggunakan alur maju. Ini bermula ketika Si Kabayan dan Ambu Kabayan sedang membereskan halaman rumah sambil berbincang-bincang. Lalu, mereka didatangi oleh Gulang-gulang yang akan memberitahu bahwa Raja Jimbul akan datang. Kejadian selanjutnya diawali dengan datangnya Raja Jimbul yang menginginkan ayam peliharaan Kabayan, Kabayan tidak menerima perlakuan Raja Jimbul yang semena-mena, lalu Kabayan berpura-pura menjadi wiku untuk mengecoh Raja Jimbul, hingga akhirnya Raja Jimbul dan para pembantunya tertipu lalu malu bukan kepayang.

\section{Tokoh dan Penokohan}

Terdapat tujuh tokoh dalam cerita ini dengan watak-watak seperti dibawah ini.

a. Kabayan berwatak sederhana dalam berpikir, tidak takut kepada siapapun, pintar dalam mengakali orang lain, kritis terhadap ketidakadilan, dan banyak akal.

b. Ambu Kabayan berwatak bisa diajak bekerja sama dan menuruti perintah suami. 
c. Raja Jimbul berwatak serakah, mudah ditipu, dan ambisius.

d. Gulang-Gulang, Patih, Mantri Jero, dan Parekan berwatak taat perintah Raja.

\section{Latar}

Latar yang terdapat dalam naskah ini sebanyak 21 latar yang meliputi latar sosial dan latar geografis.

\section{Sudut Pandang}

Sudut pandang yang dipakai pengarang dalam cerita ini adalah sudut pandang orang ketiga, karena pengarang memakai nama pada tokoh-tokohnya.

\section{Gaya Bahasa}

Terdapat 11 gaya bahasa dalam cerita ini, yakni gaya bahasa eufimisme, gaya basa epitet, gaya bahasa perumpamaan, gaya bahasa ironi, gaya bahasa alegori, gaya basa retoris, gaya bahasa satire, dan gaya bahasa paradoks.

\section{Struktur Dramatik}

Struktur dramatik dalam naskah gending karesmen "Si Kabayan jeung Raja Jimbul" dijelaskan seperti di bawah ini.

a. Terdapat prolog dalam cerita ini.

b. Dialog dalam cerita ini sebanyak 182 .

c. Tidak terdapat babak dalam cerita ini.

d. Cerita ini dibangun oleh 12 adegan yang dibagi menjadi adegan hiburan, adegan ngiket/suspense, adegan berat, adegan hal.u, dan adegan wajib.

e. Wawancang dalam cerita ini sebanyak 21 wawancang. Sebagian besar wawancang menunjukkan perintah untuk pelaku.

f. Dalam cerita ini terdapat 1 solilokui dalam 12 adegan, yang diucapkan oleh Kabayan dan Ambu Kabayan.

g. Dalam cerita ini tidak terdapat aside.

h. Tidak terdapat epilog dalam naskah ini.

Dalam naskah ini pun terdapat sastra lagu. Sastra lagu yang ditemukan yakni sisindiran, kawih, dan kakawihan.

\section{Aspek Psikosastra}

Aspek psikosastra dalam naskah gending karesmén "Si Kabayan jeung Raja
Jimbul" mencakup kebutuhan dasar manusia meliputi kebutuhan fisiologis (jasad), kebutuhan terhadap rasa aman, kebutuhan terhadap rasa memiliki-dimiliki, kebutuhan terhadap penghargaan, dan kebutuhan aktualisasi diri.

\section{Kebutuhan Fisiologis}

Kebutuhan fisiologis (jasad) menurut Maslow meliputi kebutuhan makan, minum, tidur, dan tempat. Beberapa analisisnya dibahas di bawah ini.

Teks:

KABAYAN

Lalagedayan deuh... lalagedayan

E... ngeunah pipikiran.

\begin{abstract}
AMBU KABAYAN
Nunang naning nuninang nunang $n u$ nanung
\end{abstract}

\section{KABAYAN}

Hirup ukur laladangan, dadagangan. (Dialog1-3 $\rightarrow$ hal.1)

Dari dialog di atas terlihat bahwa kebutuhan fisiologis Si Kabayan dan Ambu Kabayan sudah terpenuhi. Sebab dari Si Kabayan berleha-leha di kursi adalah dia sudah tidak dihantui oleh ketakutan untuk tidak makan, tidur, minum, dan tempat tinggal.

Kelakuan Kabayan yang seperti itu memperlihatkan bahwa Kabayan sudah terpenuhi segala keperluannya, atau paling tidak dia sudah tidak dihantui ketakutan akan makan, minum, tidur, dan tempat tinggal. Hal ini pun terlihat dari sikap $\mathrm{Ka}$ bayan yang sudah "héhéotan" atau bersiul. Bersiul merupakan kegiatan seseorang yang sudah tenang dan santai.

\section{Kebutuhan terhadap rasa aman}

Kabutuhan terhadap rasa aman meliputi bebas dari rasa tidak aman, bebas dari rasa takut dan rasa bingung, dan bebas dari masalah hukum. Adapun beberapa analisisnya akan di bahas di bawah ini. 
Teks:
ADEGAN 4
Si Kabayan sanggeus ungkleuk- ungkleukan, tuluy sasaréan peureum hayam.
Gulang-Gulang duanana bengong...
Raja Jimbul datang ka hareupeun imah
Si Kabayan...
Gulang-Gulang duanana bengong...
Raja Jimbul datang hareupeun imah Si
Kabayan.
Gulang-Gulang nu duaan téa gancang acong-acongan nyembah.
Eta Raja téh maké pakéan nu araranéh.
(wawancangH $\rightarrow$ hal. 4)

Dialog di atas menunjukkan bahwa Kabayan tidak mempedulikan perintah Gulang-gulang. Gulang-gulang dibuat bingung sebab ada orang yang berani menampik perintah, dan tidak mau menyambut raja. Ketakutan Gulang-gulang semakin bertambah ketika halaman rumah Kabayan kotor. Dan ketika Raja Jimbul datang, Gulang-gulang menyembah Raja karena merasa tidak melaksanakan tugas dengan baik.

Lantaran status Raja Jimbul sebagai pemilik kerajaan, Raja Jimbul pun berpikir bahwa seluruh isi kerajaan adalah miliknya, termasuk ayam milik Kabayan yang akan ditangkap. Ketika pembantu Raja Jimbul akan menangkap ayam milik Kabayan, seketika Kabayan berdiri dan berkata tapi si pelung nu Si Kabayan, Raja nu ngaraja aing (tapi ayam itu milik Kabayan, Raja yang merajai diri sendiri). Para pembantu raja seketika kaget karena ada orang yang berani melawan kehendak Raja Jimbul, sehingga mereka mundur dan merasa takut.

\section{Kebutuhan terhadap Rasa Memiliki- Dimiliki}

Kebutuhan terhadap rasa cinta atau memiliki-dimiliki merupakan kebutuhan ketiga setelah kebutuhan fisiologis dan kebutuhan terhadap rasa aman terpenuhi.
Kebutuhan ini merupakan dorongan jika seseorang mempunyai keinginan untuk membuat suatu hubungan batin dengan orang lain. Beberapa analisisnya akan dibahas di bawah ini.

Teks:

KABAYAN

Heuheuy, heuheuy

Uing jadi kasép

Uing jadi Raja, deuleu!

Heuheuy, heuheuy

Manéh ka nagari

Manéh praméswari, daék?

\author{
KABAYAN/AMBU KABAYAN \\ Raja cék urang \\ Praméswari cék urang \\ Urang mah kumaha urang \\ Lain? Heuy! \\ (dialog 181-182 $\rightarrow$ hal. 15)
}

Dalam cerita ini, Kabayan memiliki rasa memiliki-dimiliki (cinta). Dengan bukti bahwa Kabayan memiliki istri yaitu Ambu Kabayan. Dalam dialog di atas terlihat bahwa Kabayan tidak lupa terhadap istrinya ketika memakai baju raja, dengan mengajak istrinya untuk menjadi permaisuri, meskipun hanya dalam impian.

\section{Kebutuhan terhadap Penghargaan}

Kebutuhan terhadap penghargaan meliputi keinginan terhadap kekuatan, prestasi, keunggulan, kemampuan, ketenaran, kemulyaan, pengalaman, perhatian, arti penting, martabat, dan apresiasi. Kebutuhan ini bersumber dari diri sendiri dan lingkungan sekitar. Adapaun beberapa analisisnya dibahas seperti di bawah ini.

\section{Teks:}

Gulang-Gulang ti jero mula geus méré iberan yén Raja Jimbul rék datang...

RS LALAKI

Bungbang! Bungbang!

Raja Jimbul rék ngalanglang

Anu mulya Raja Jimbul

Sumping! Sumping! 


\author{
KABAYAN \\ Raja Jimbul! Raja Jimbul \\ Jebul! Jebul! \\ RS LALAKI \\ Bungbung! Bungbung! \\ Raja Jimbul rék ngalangkung \\ Anu mulya Raja Jimbul \\ Rawuh! Rawuh! \\ (wawancang C, dialog 35-37 $\rightarrow$ hal. 3)
}

Aspek kebutuhan terhadap penghargaan terlihat dalam dialog ini. Gulanggulang mengabari masarakat bahwa Raja Jimbul akan datang, dengan begitu masyarakat harus menyambut raja dengan baik. Penghargaan terhadap raja sangat diinginkan dalam dialog ini.

\section{Aktualisasi diri}

Kebutuhan dasar paling tinggi tingkatannya adalah kebutuhan terhadap aktualisasi diri. Setiap orang berusaha untuk bisa mengaktualisasikan kemuampuannya atau memperlihatkan potensi yang dimiliki. Supaya lebih jelas, berikut beberapa analisis akan dibahas di bawah ini.

\section{Teks:}

\section{GULANG-GULANG}

Enya ayeuna purunkeun

Hayoh! Gancang!

Ayeuna purunkeun

\section{KABAYAN \\ Purun mah aya di uing \\ Niat gé uing nu oga \\ Eunteu ulun eunteu iat \\ Aduh...ngeunah nguliat... \\ (dialog 48-49 $\rightarrow$ hal. 4)}

Kabayan mengaktualisasikan dirinya dengan cara menampik perintah yang semena-mena dari Gulang-gulang. Aktualisasi Kabayan terlihat dari tidak adanya rasa takut terhadap pembantu raja yang menyuruh seenaknya. Tentu tidak semua pelaku bisa melakukan itu. Perilaku tersebut dapat dilakukan ketika seseorang sudah terpenuhi semua kebutuhannya.

\section{Nilai Pendidikan Karakter}

Nilai pendidikan karakter adalah usaha untuk menerapkan nilai-nilai positif dalam meningkatkan nilai diri manusia yang baik sikapnya. Selain menurut Koesoema (2007: 114), terdapat 12 nilai pendidikan karakter yang terdapat dalam teks ini, yakni jujur, toleransi (silih ajénan), disiplin, kerja keras (gawé soson-soson), kreatif (rancagé), mandiri(motékar), demokratis, menghargai prestasi (ngajénan préstasi), bersahabat/ komunikatif (soméah), cinta damai (répéh-rapih), peduli sosial (tulungtinulungan) dan tanggung jawab. Lebih jelasnya dibahas di bawah ini.

\section{Jujur}

Karakter jujur merupakan nilai manusia yang mencakup perbuatan yang dapat dipercaya dalam bicara, berkelakuan, dan bekerja. Analisis kejujuran dibahas di bawah ini.

Kabayan yang tidak ingin membersihkan halaman rumahnya menunjukkan sikap yang jujur. Rakyat tidak seharusnya menyembunyikan kondisi dan keadaan mereka yang sebenarnya ketika raja tiba, justru harus memperlihatkan apa yang dialami mereka. Itu yang diperlihatkan oleh Kabayan dalam dialog ini.

\section{Toleransi}

Nilai karakter toleransi merupakan nilai sikap dan perbuatan manusia yang menghargai perbedaan agama, suku, etnis, pendapat, sikap, dan sifat orang lain yang berbeda. Ada beberapa dialog yang menunjukkan nilai karakter toleransi dibahas di bawah ini.

Sikap toleransi Kabayan muncul dalam dialog. Dia menjadi penengah dari pelakupelaku yang sedang bertengkar memperebutkan Nyi Putri. Dalam dialog disebutkan, pelaku bertengkar karena memiliki kemauan dan tidak mempedulikan orang lain.

\section{Kreatif}

Nilai karakter kreatif merupakan nilai manusia dalam cara berpikir dan cara dalam 
melakukan suatu hal untuk menghasilkan hal-hal yang baru.

\section{Teks:}

Si Kabayan rada nyegé hareupeun Raja Jimbul. Teu lila raja jatémbong mengkék irungna. Rét ka Patih. Patih bari nunjuk kana bujur Si Kabayan. Tiluanana nu aya ditukangeun Si Kabayan mengkék irung...

(wawancang O, dialog 138-141 $\rightarrow$ hal. 10-11)

Perbuatan Kabayan yang bisa mengaitkan kentut dengan kedatangan Batara Asmara termasuk kreatif, meskipun mungkin negatif, tapi dengan idenya, para tamu kerajaan terpaksa menuruti perintah Kabayan.

\section{Mandiri}

Nilai karakter mandiri merupakan nilai manusia yang mencakup nilai sikap dan perbuatan yang tidak tergantung kepada orang lain dalam mengerjakan tugastugasnya.

\section{Teks:}

\section{GENDING}

Si Kabayan ngadéhém tarik pisan, Raja Jimbul ngagebeg. Sanggeus kanyahoan euweuh, tuluy nyalukan Parekan...Haharéwosan..

(wawancang K, dialog 146$150 \rightarrow$ hal. 11-12)

Sikap mandiri ditunjukkan oleh Raja Jimbul yang sudah tidak ingin meminta bantuan Kabayan, karena Raja Jimbul yakin dapat bertemu Nyi Putri tanpa bantuan Kabayan.

\section{Demokratis}

Nilai karakter demokratis merupakan nilai manusia dalamcara berpikir, sikap, dan perbuatan yang menganggap sama hak dan kewajiban yang dimilikinya dan orang lain.
Sikap Kabayan disebutkan menuntut adanya toleransi dan demokrasi. Kabayan merasa tidak dihargai oleh para tamu kerajaan. Dia melayangkan protes kepada Gulang-gulang, sebab memerintahkan suatu hal yang tidak disukai Kabayan. Proses demokrasi terlihat dari cara protes yang tentunya berbeda.

\section{Menghargai Prestasi}

Nilai karakter menghargai prestasi merupakan nilai sikap dan perbuatan untuk menghasilkan hal yang bermanfaat untuk masyarakat dan menghargai serta menghormati prestasi orang lain. Sikap menghargai prestasi terlihat ketika Raja Jimbul memerintahkan Parekan untuk terus memanggil Nyi Putri, dia mempunyai keyakinan bahwa Parekan dapat mendatangkan Putri.

\section{Bersahabat/Komunikatif}

Nilai karakter bersahabat/komunikatif merupakan nilai manusia yang ramah dan bisa bekerja sama dengan orang lain.

Dalam dialog disebutkan bahwa Raja Jimbul bersedia untuk bekerja sama dengan Kabayan sampai-sampai dian memohon, hal yang sepatutnya kurang bagus dilakukan raja terhadap rakyatnya.

\section{Cinta Damai}

Nilai karakter cinta damai merupakan nilai manusia yang meliputi sikap, ucapan, dan perbuatan yang menyebabkan orang lain merasa senang dan aman.

Kabayan termasuk orang yang tidak pernah mengganggu siapapun. Dan imbasnya dia tidak pernah diganggu oleh orang lain. Dalam kehidupan sehari-hari, jikalau dalam menjalani hidup tidak mengganggu orang lain, tentu orang lain pun tidak akan mengganggu kita.

\section{Peduli Sosial}

Nilai karakter peduli sosial merupakan nilai kemanusiaan yang mencakup sikap dan perbuatan untuk selalu memberikan bantuan kepada orang lain. 
Dalam dialog ini Raja Jimbul memberikan bantuan kepada masyarakat yang membutuhkan, dalam hal ini yaitu memenuhi kemauan Kabayan untuk mendatangkan perempuan cantik supaya Nyi Putri keluar dari tempat persembunyiannya.

\section{Tanggung Jawab}

Nilai karakter tanggung jawab merupakan nilai manusia yang mencakup sikap dan perbuatan seseorang untuk melaksanakan tugas dan kewajibannya.

Raja jimbul dalam dialog ini selalu berusaha untuk bertemu dengan Nyi Putri, tentu untuk mewujudkan keinginannya, Raja Jimbul harus berusaha keras agar tujuannya tercapai. Sikap tanggung jawab juga ditunjukkan oleh Parekan yang terus memanggil Nyi Putri agar dapat membantu Raja Jimbul mencapai keinginannya.

\section{SIMPULAN}

Naskah gending karesmen merupakan salahsatu medium untuk menajarkan nilai pendidikan karakter. Nilai pendidikan karakter tentu ada dalam tingkah laku pelaku yang perbuatan dan ucapannya menjadi cermin bagi pembaca, sebab pelaku dalam naskah gending karesmen merupakan refleksi dari kehidupan nyata yang diolah oleh sastrawan. Naskah gending karesmen "Si Kabayan jeung Raja Jimbul" merupakan naskah gending karesmen rumpaka rekaan, sebab ceritanya hasil adaptasi dari cerita ra'yat yakni Kabayan.

Pelaku-pelaku dalam naskah ini banyak mengandung nilai pendidikan karaker. Sebanyak 41 tingkah laku dan ucapan pelaku yang didalamnya terdapat 12 nilai pendidikan karakter. Nilai pendidikan karakternya yakni jujur, toleransi (silih ajénan), disiplin, kerja keras (gawé sosonsoson), kreatif (rancagé), mandiri(motékar), demokratis, menghargai prestasi (ngajénan préstasi), bersahabat/ komunikatif (soméah), cinta damai (répéh-rapih), peduli sosial (tulung-tinulungan) dan tanggung jawab.
Hubungan antara nilai pendidikan karakter dan aspék psikosatra adalah aspek kebutuhan terhadap rasa aman sebanyak 12 data, sedangkan aspek psikosastra yang paling sedikit mengandung nilai pendidikan karakter adalan kebutuhan terhadap rasa dimiliki-memiliki. Sisanya aspék kebutuhan fisiologis terdapat 9 data, kebutuhan terhadap penghargaan 7 data, dan kebutuhan terhadap aktualisasi diri sebanyak 6 data.

Pelaku-pelaku dalam naskah ini kebanyakan mempunyai watak yang kurang baik. Sehingga apabila diajarkan di sekolah, guru harus lebih selektif memilih bahan mana yang cocok dipakai untuk diajarkan kepada siswa.

\section{PUSTAKA RUJUKAN}

Endraswara, Suwardi. 2007. Metode Penelitian Psikologi Sastra: Teori, Langkah, Penerapannya. Yogyakarta: MedPress

Hasanudin, W.S. 1996. Drama: Karya dalam Dua Dimensi. Bandung: Angkasa.

Iskandarwassid. 1996. Kamus Istilah Sastra: Pangdeudeul Pangajaran Sastra Sunda. Bandung: Geger Sunten.

Koesoema, A. Darmo. 2007. Pendidikan Karakter Strategi Mendidik Anak di Jaman Global. Jakarta: PT. Gramedia Natapraja, Iwan. 2003. Sekar Gending. Bandung: PT. Karya Cipta Lestari.

Soemardjo, Jakob. 2014. Paradoks Cerita Si Kabayan. Bandung: Yrama Widya

Sopandi, Atik. Dkk. 1994. Ragam Cipta: Mengenal Seni Pertunjukkan Jawa Barat. Bandung: CV. Sampurna.

\section{UCAPAN TERIMA KASIH}

Ucapan terima kasih saya sematkan kepada Allah SWT karena telah memberi kesehatan lahiriah maupun batiniah sehingga dapat menyelesaikan artikel ini. Terima kasih juga saya ucapkan kepada kedua orang tua saya, para dosen, Bapa Wahyu Wibisana dan sahabat-sahabat saya yang telah mendukung dan membantu menyelesaikan karya tulis ini. 